\title{
SISTEM DETEKSI KERUSAKAN BEARING RODA PADA MOBIL MENGGUNAKAN SENSOR PIEZOELECTRIK BERBASIS ANDROID
}

\author{
M Cecep Zaelani \#) \\ \#)Program Studi IImu Komputer, FMIPA, Universitas Pakuan, Bogor, Indonesia \\ \#)Corresponding Author: theflixs@gmail.com
}

Article history: received 25 march 2019; revised 7 June 2019; accepted 26 June 2019

\begin{abstract}
Abstrak
Kerusakan bearing pada roda mobil telah mendorong beberapa penelitian untuk membuat sistem yang mampu mendeteksi kerusakan bearing roda tersebut. Untuk mengatasi masalah tersbut, telah dibangun dan diuji sistem deteksi kerusakan bearing roda pada mobil menggunakan sensor piezoelectrik. Hasil penelitian menunjukkan sensor piezoelektrik mendeteksi kerusakan bearing pada roda berdasarkan frekuensinya yaitu 0 - $5 \mathrm{~Hz}$ bagus, 6 $30 \mathrm{~Hz}$ kurang bagus, dan $31-355 \mathrm{~Hz}$ rusak parah. Data dapat di tampilkan secara realtime melalui android. Hasil dari penelitian ini dapat digunakan pada dealer atau tempat reparasi mobil.
\end{abstract}

Kata kunci: bearing roda, sensor piezelektrik, android

\begin{abstract}
Bearing damage to the car's wheels has prompted several studies to create a system capable of detecting damage to the wheel bearings. To overcome this problem, a wheel bearing damage detection system has been built and tested using a piezoelectric sensor. The results showed that piezoelectric sensors detect bearing damage to the wheels based on their frequency, which is $0-5 \mathrm{~Hz}$ is good, $6-30 \mathrm{~Hz}$ is not good, and $31-355 \mathrm{~Hz}$ is badly damaged. Data can be displayed in realtime via Android. The results of this study can be used at dealers or car repair centers.
\end{abstract}

Keywords: wheel bearing, piezoelectric sensor, android

\section{Pendahuluan}

Keselamatan pengendara ketika melakukan perjalanan dipengaruhi oleh kondisi kendaraan. Salah satu yang harus dicermati pada kondisi kendaraan adalah gejala kerusakan pada bearing roda [1]. Karena posisinya yang tersembunyi, tidak mudah bagi pengendara untuk memantau kondisi bearing tersebut. Untuk itu, perlu dirancang alat yang dapat membantu pengendara memantau secara otomatis kondisi bearing kendaraan roda empat (mobil). Perkembangan teknologi elektronika memungkinkan dikemasnya perangkat prosesor, memori, dan input/output (I/O) dalam satu integrated circuit yang disebut sebagai mikrokontroloer. Mikrokontroller telah luas diaplikasikan dalam berbagai perangkat mulai dari timbangan digital [2] hingga alat pengontrol intensitas cahaya ruangan [3]. sistem pendeteksi kerusakan bearing pada kendaraan roda empat melalui deteksi getaran yang dihasilkan oleh putaran roda. Sistem ini akan memberikan informasi kondisi bearing roda secara real time. Sensor membaca getaran bearing roda, kemudian Dengan kemampuanya, mikrokontroler juga dapat digunakan untuk mengumpulkan dan memproses data serta menghubungkan sensor dan perangkat antarmuka alat pemantauan bearing roda kendaraan. Pemantauan kondisi bearing dapat dilakukan dengan mendeteksi getaran pada roda. Pada penelitian sebelumnya, deteksi dan pemrosesan data getaran telah dilakukan untuk identifikasi kerusakan bantalan pada mesin rotasi [4] maupun 
identifikasi gangguan pada komponen mesin [5]. Penelitian tersebut berhasil menangkap dan membaca analisa kerja mesin. Hasil pengukuran ditampilkan pada LCD dan komputer, kemudian hasil pada komputer diplot ke dalam sebuah grafik. Selain diplot, hasil pengukuran juga disimpan ke dalam sebuah file menggunakan data logger. Salah satu sensor yang dapat digunakan untuk mendeteksi bearing roda adalah SWS [6]

Alarm dapat dibuat untuk mendeteksi adanya gempa menggunakan sensor sebagai pendeteksi getaran. Novianta [7] telah membuat alat untuk mendeteksi sinyal getaran dalam arah vertikal maupun arah horizontal menggunakan pegas yang terpasang di permukaan sensor piezoelektrik. Pengujian dilakukan dengan menjatuhkan suatu benda dengan beban yang tetap tetapi bervariasi pada jarak jatuh ke sensor. Pelaratan tersebut cukup peka dalam mendeteksi getaran dari jarak $10 \mathrm{~cm}$ sampai dengan $100 \mathrm{~cm}$. Afriani [8] melakukan penelitian dengan menggunakan sensor efek Hall UGN3503 sebagai detektor gempa dengan keluaran berupa bunyi alarm yang dapat bekerja dengan baik [9] melakukan penelitian menggunakan sensor posisi Faraday untuk pendeteksi dini gempa. Sistem ini dirancang untuk mendeteksi gempa dan memberikan peringatan alarm saat terjadi gempa. Sistem ini dapat berkerja dengan baik yang ditunjukan dengan nilai linieritas rangkaian dalam mendeteksi sinyal getaran sebesar $=0,935$.

Pada penelitian ini dikembangkan sistem deteksi kerusakan bearing roda pada mobil menggunakan sensor piezoelectrik dengan display android. sensor piezoelektrik dikenal mampu mendeteksi frekuensi getaran secara akurat rentang $1000 \mathrm{~Hz}-40.000 \mathrm{HZ}$ [10]. Sistem dapat memberikan informasi getaran pada bearing hingga notifikasi pergantian ban melalui android

\section{Metode penelitian}

Metode penelitian dilakukan sesuai diagram alir pada gambar 1

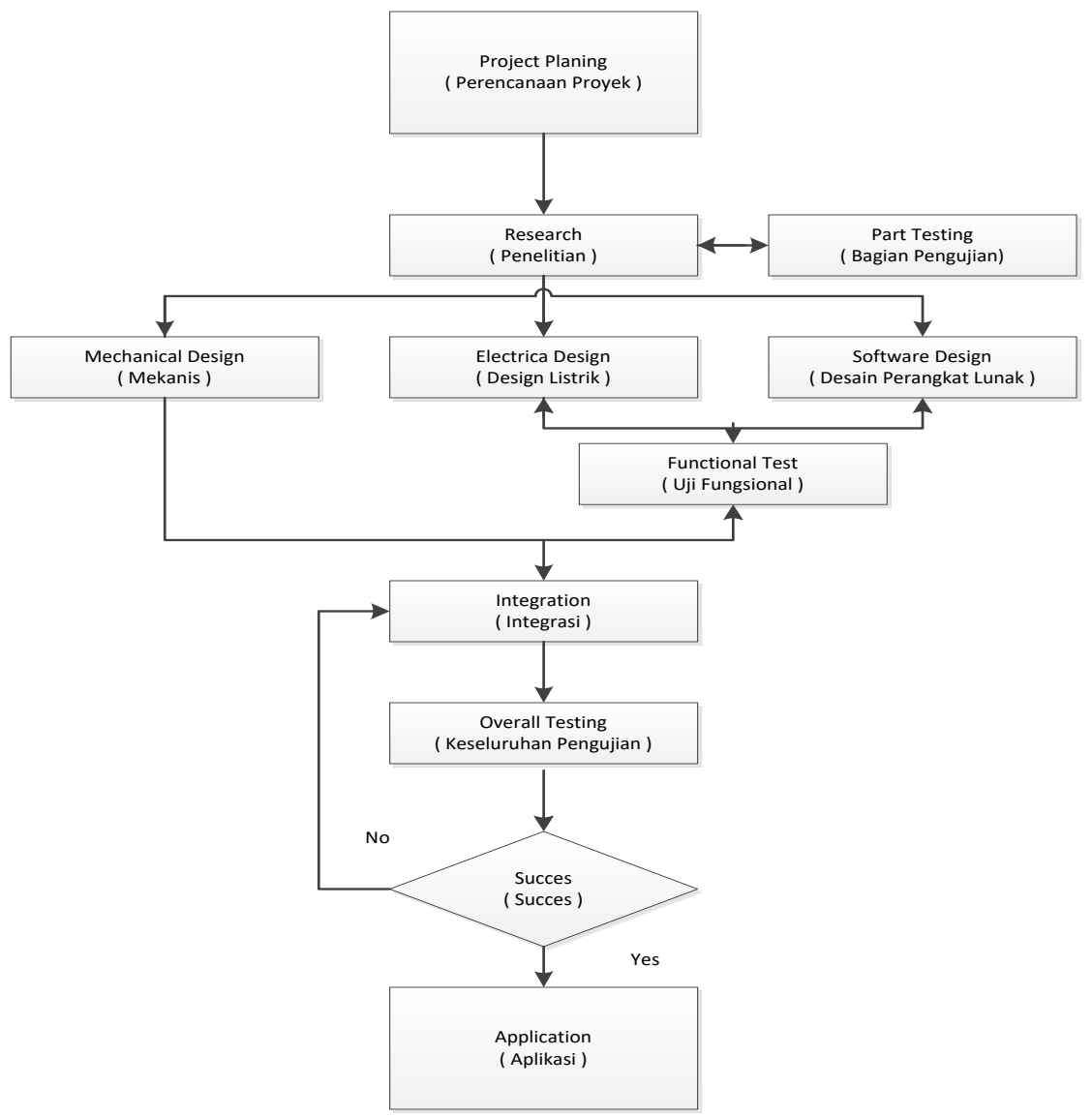

Gambar 1. Metode Penelitian Hardware Programing. 
Tahap perencanaan proyek penelitian adalah tahapan kegiatan dari proses pembuatan system. Komponen yang dibutuhkan dalam perencanaan system adalah module arduino uno, sensor piezoelectrik, kabel jumper, bluetooth HC-06. Setelah perencanaan sistem, kemudian dilanjutkan dengan penelitian awal dari sistem yang akan dibuat. Pada tahap penelitian dilakukan perancangan awal rangkaian mekanik serta komponen dari model sistem pengamanan ini untuk memastikan bahwa semua komponen dapat berjalan dengan optimal. Sistem ini menggunakan sebuah module arduino uno. Tahap berikutnya dilakukan pengetesan komponen-komponen yang akan digunakan menggunakan multimeter. Pengetesan menggunakan arduino serial monitoring dilakukan dengan melihat output tiap komponen yang terhubung dengan arduino uno melalui koneksi kabel USB. Pengujianmenggunakan multimeter meliputi pengujian tegangan input dan output setiap komponen. Test fungsional dilakukan terhadap integrasi tahap desain sistem listrik dan desain software setelah komponen saling terhubung satu sama lain, dan software di-uplod selanjutnya di tes apakah terjadi bug atau error. Hal ini untuk meningkatkan perfoma alat yang sudah dirancang. Tes fungsional keseluruhan sistem (Overall Testing) dilakukan setelah integrasi dan perakitan alat mobil selesai, pada tahap ini alat akan diuji secara keseluruhan dan dicek kendala alat terhadap benda yang akan di lakukan pengukuranya itu bearing.

\section{Analisis dan Hasil}

Dari hasil penelitian ini penulis menyelesaikan bebera pahal yang menjadi acuan referensi agar mendapatkan hasil secara maksimal dengan megusahakan desain model sesederhana mungkin yang terbuat dari sebuah box dengan menggunakan modul Arduino Uno yang saling berhubungan dengan komponen lainnya. Modul arduino uno terhubung dengan sebuah module Bluetooth untuk bisa berkomunikasi dengan android dan piezoelectric sebagai sensor untukmenangkapgetaran yang dihasilkan oleh bearing rodamobil, tampilan pada android dapat dilihat pada gambar 2 .
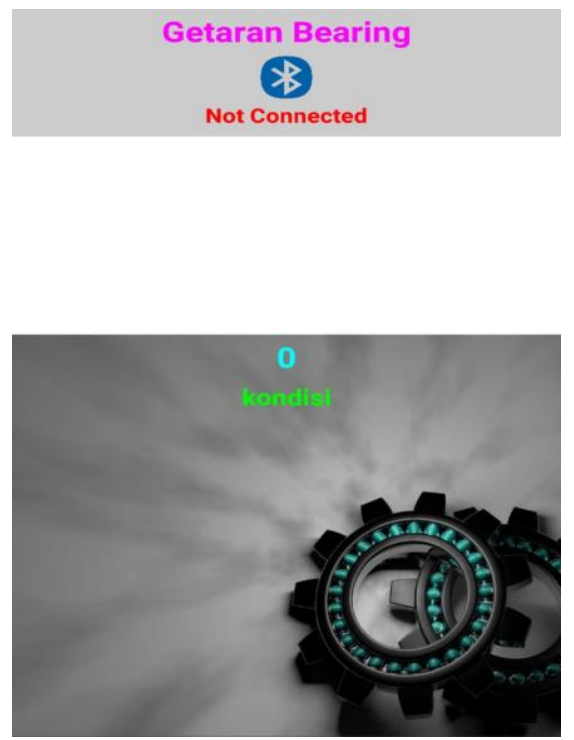

Gambar 2. Hasil Output di Android

Deteksi kerusakan bearing roda pada mobil menggunakan beberapa komponen yaitu modul arduino uno, modul bluetooth dan sensor piezoelectrik. Model akan secara otomatis mengirim data ke android berupa frekuensi gelombang yang dihasilkan dari pengecekan yang dilakukan dengan cara menempelkan sensor piezoelectric terhadap knuckle roda mobil. Pada model sistem ini terdapat 3 parameter yang menjadi acuan pengukuran, 1. Bearing dalam kondisi bagus, 2. bearing dalam kondisi rusak ringan dan 3 . bearing dalam kondisi rusak parah sebagaimana dapat dilihat pada Tabel 1. 
KOMPUTASI (Jurnal IImiah IImu Komputer dan Matematika)

Vol.16, No.2, Juli 2019, Hal. $296-302$

P-ISSN: 1693-7554, E-ISSN: 2654-3990

https://journal.unpak.ac.id/index.php/komputasi

Tabel 1. Uji cobaalat pada spring shock absorber roda

\begin{tabular}{|c|c|c|c|c|}
\hline No & Kendaraan & Bearing roda & Frekuensi & Keterangan \\
\hline \multirow[t]{4}{*}{1} & Terrios 2008 & Depan kanan & 0 & Bagus \\
\hline & & Depan kiri & 25 & Rusak sedang \\
\hline & & Belakang kanan & 1 & Bagus \\
\hline & & Belakang kiri & 1 & Bagus \\
\hline \multirow[t]{4}{*}{2} & Xenia 2003 & Depan kanan & 76 & Rusak parah \\
\hline & & Depan kiri & 16 & Rusak sedang \\
\hline & & Belakang kanan & 2 & Bagus \\
\hline & & Belakang kiri & 4 & Bagus \\
\hline \multirow[t]{5}{*}{3} & Sigra 2018 & Depan kanan & 2 & Bagus \\
\hline & & Depan kiri & 1 & Bagus \\
\hline & & Belakang kanan & 0 & Bagus \\
\hline & & Belakang kiri & 0 & Bagus \\
\hline & & & & Bagus \\
\hline \multirow[t]{4}{*}{4} & Ayla 2017 & Depan kanan & 1 & Bagus \\
\hline & & Depan kiri & 1 & Bagus \\
\hline & & Belakang kanan & 1 & Bagus \\
\hline & & Belakang kiri & 0 & Bagus \\
\hline \multirow[t]{4}{*}{5} & Grandmax & Depan kanan & 24 & Rusak sedang \\
\hline & 2012 & Depan kiri & 59 & Rusak parah \\
\hline & & $\begin{array}{l}\text { Belakang kanan } \\
\text { Belakang kiri }\end{array}$ & $\begin{array}{l}208 \\
171\end{array}$ & $\begin{array}{l}\text { Rusak parah } \\
\text { Rusak parah }\end{array}$ \\
\hline & & & & Tlusan palait \\
\hline
\end{tabular}

Pada tabel 1 , sensor piezoelektrik berhasil mendeteksi getaran bearing roda pada spring shock absorber roda. Hasil menunjukkan bahwa perlu adanya penggantian roda depan pada Xenia 2003 dan roda depan kiri, belakang kanan, dan belakang kiri untuk Grandmax 2012 sebagaimana pada tabel 2 .

Tabel 2. Uji coba alat pada knuckle roda depan

\begin{tabular}{|c|c|c|c|c|}
\hline No & Kendaraan & Bearing roda & Frekuensi & Keterangan \\
\hline \multirow[t]{4}{*}{1} & Terrios 2008 & Depan kanan & 0 & Bagus \\
\hline & & Depan kiri & 10 & Rusak sedang \\
\hline & & Belakang kanan & 1 & Bagus \\
\hline & & Belakang kiri & 1 & Bagus \\
\hline \multirow[t]{4}{*}{2} & Xenia 2003 & Depan kanan & 22 & Rusak sedang \\
\hline & & Depan kiri & 5 & Bagus \\
\hline & & Belakang kanan & 2 & Bagus \\
\hline & & Belakang kiri & 4 & Bagus \\
\hline \multirow[t]{4}{*}{3} & Sigra 2018 & Depan kanan & 0 & Bagus \\
\hline & & Depan kiri & 0 & Bagus \\
\hline & & Belakang kanan & 0 & Bagus \\
\hline & & Belakang kiri & 0 & Bagus \\
\hline \multirow[t]{4}{*}{4} & Ayla 2017 & Depan kanan & 0 & Bagus \\
\hline & & Depan kiri & 0 & Bagus \\
\hline & & Belakang kanan & 1 & Bagus \\
\hline & & Belakang kiri & 0 & Bagus \\
\hline
\end{tabular}




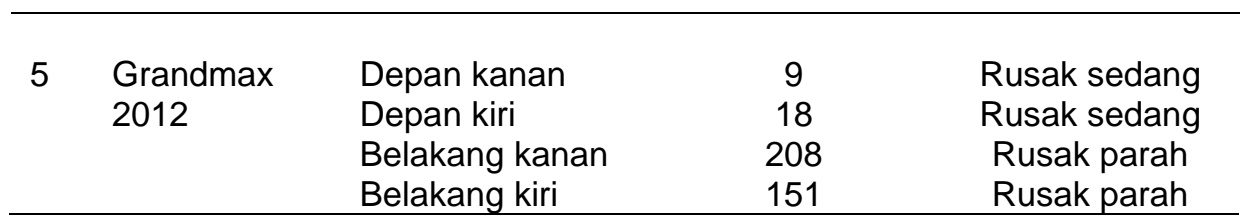

Untuk tabel 2, sensor piezoelektrik berhasil mendeteksi getaran bearing roda pada knuckle roda depan. Hasil menunjukkan bahwa perlu adanya penggantian roda belakang kanan dan belakang kiri untuk Xenia 2003.

Tabel 3. Uji coba alat pada shock absorber roda

\begin{tabular}{|c|c|c|c|c|}
\hline No & Kendaraan & Bearing roda & Frekuensi & Keterangan \\
\hline 1 & Terrios 2008 & $\begin{array}{l}\text { Depan kanan } \\
\text { Depan kiri } \\
\text { Belakang kanan } \\
\text { Belakang kiri }\end{array}$ & $\begin{array}{c}0 \\
14 \\
1 \\
1\end{array}$ & $\begin{array}{c}\text { Bagus } \\
\text { Rusak sedang } \\
\text { Bagus } \\
\text { Bagus }\end{array}$ \\
\hline 2 & Xenia 2003 & $\begin{array}{l}\text { Depan kanan } \\
\text { Depan kiri } \\
\text { Belakang kanan } \\
\text { Belakang kiri }\end{array}$ & $\begin{array}{l}51 \\
6 \\
0 \\
1\end{array}$ & $\begin{array}{c}\text { Rusak parah } \\
\text { Rusak sedang } \\
\text { Bagus } \\
\text { Bagus }\end{array}$ \\
\hline 3 & Sigra 2018 & $\begin{array}{l}\text { Depan kanan } \\
\text { Depan kiri } \\
\text { Belakang kanan } \\
\text { Belakang kiri }\end{array}$ & $\begin{array}{l}0 \\
0 \\
0 \\
0\end{array}$ & $\begin{array}{l}\text { Bagus } \\
\text { Bagus } \\
\text { Bagus } \\
\text { Bagus }\end{array}$ \\
\hline 4 & Ayla 2017 & $\begin{array}{l}\text { Depan kanan } \\
\text { Depan kiri } \\
\text { Belakang kanan } \\
\text { Belakang kiri }\end{array}$ & $\begin{array}{l}0 \\
0 \\
0 \\
0\end{array}$ & $\begin{array}{l}\text { Bagus } \\
\text { Bagus } \\
\text { Bagus } \\
\text { Bagus }\end{array}$ \\
\hline 5 & $\begin{array}{l}\text { Grandmax } \\
2012\end{array}$ & $\begin{array}{l}\text { Depan kanan } \\
\text { Depan kiri } \\
\text { Belakang kanan } \\
\text { Belakang kiri }\end{array}$ & $\begin{array}{l}10 \\
37 \\
98 \\
63 \\
\end{array}$ & $\begin{array}{l}\text { Rusak sedang } \\
\text { Rusak parah } \\
\text { Rusak parah } \\
\text { Rusak parah }\end{array}$ \\
\hline
\end{tabular}

Pada tabel 3, sensor piezoelektrik berhasil mendeteksi getaran shock absorber roda pada shock absorber roda. Hasil menunjukkan bahwa perlu adanya penggantian roda depan pada Xenia 2003 dan roda depan kiri, belakang kanan, dan belakang kiri untuk Grandmax 2012.

Tabel 4. Uji coba alat pada long tie rod depan

\begin{tabular}{lllcc}
\hline No & Kendaraan & Bearing roda & Frekuensi & Keterangan \\
\hline 1 & Terrios 2008 & Depan kanan & 0 & Bagus \\
& & Depan kiri & 14 & Rusak sedang \\
& & Belakang kanan & 1 & Bagus \\
& & Belakang kiri & 1 & Bagus \\
\multirow{5}{*}{2} & \multirow{4}{*}{ Xenia 2003 } & Depan kanan & 51 & Rusak parah \\
& & Depan kiri & 6 & Rusak sedang \\
& & Belakang kanan & 0 & Bagus \\
& & Belakang kiri & 1 & Bagus \\
3 & \multirow{3}{*}{ Sigra 2018 } & Depan kanan & 0 & Bagus \\
& & Depan kiri & 0 & Bagus \\
& & Belakang kanan & 0 & Bagus \\
\hline
\end{tabular}


KOMPUTASI (Jurnal IImiah IImu Komputer dan Matematika)

Vol.16, No.2, Juli 2019, Hal. $296-302$

P-ISSN: 1693-7554, E-ISSN: 2654-3990

https://journal.unpak.ac.id/index.php/komputasi

\begin{tabular}{|c|c|c|c|c|}
\hline & & Belakang kiri & 0 & Bagus \\
\hline 4 & Ayla 2017 & $\begin{array}{l}\text { Depan kanan } \\
\text { Depan kiri } \\
\text { Belakang kanan } \\
\text { Belakang kiri }\end{array}$ & $\begin{array}{l}0 \\
0 \\
0 \\
0\end{array}$ & $\begin{array}{l}\text { Bagus } \\
\text { Bagus } \\
\text { Bagus } \\
\text { Bagus }\end{array}$ \\
\hline 5 & $\begin{array}{l}\text { Grandmax } \\
2012\end{array}$ & $\begin{array}{l}\text { Depan kanan } \\
\text { Depan kiri } \\
\text { Belakang kanan } \\
\text { Belakang kiri }\end{array}$ & $\begin{array}{l}10 \\
37 \\
98 \\
63\end{array}$ & $\begin{array}{l}\text { Rusak sedang } \\
\text { Rusak parah } \\
\text { Rusak parah } \\
\text { Rusak parah }\end{array}$ \\
\hline
\end{tabular}

Untuk tabel 4, sensor piezoelektrik berhasil mendeteksi getaran bearing roda pada long tie rod depan. Hasil menunjukkan bahwa perlu adanya penggantian roda depan pada Xenia 2003 dan roda depan kiri, belakang kanan, dan belakang kiri untuk Grandmax 2012. Contoh tampilan pada android mengenai status bearing pada roda dapat dilihat pada Gambar 3.

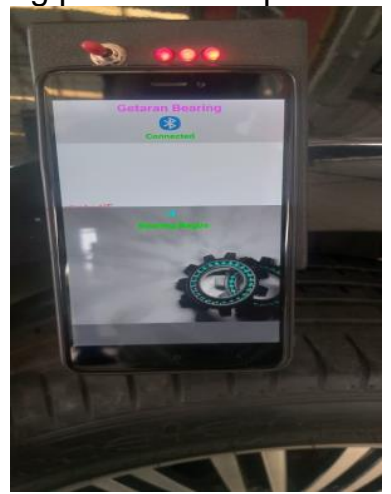

Gambar 3. Tampilkan bearing rusak di Android

\section{Kesimpulan}

Telah dibangun dan diuji sistem deteksi kerusakan bearing roda pada mobil menggunakan sensor piezoelectric telah diuji dengan baik. Hasil penelitian menunjukkan sensor piezoelektrik mendeteksi kerusakan bearing pada roda berdasarkan frekuensinya yaitu $0-5 \mathrm{~Hz}$ bagus, $6-$ $30 \mathrm{~Hz}$ kurang bagus, dan $31-355 \mathrm{~Hz}$ rusak parah. Untuk pengujian spring shock absorber roda, knuckle roda depan, shock absorber roda, dan long tie rod depan diketahui bahwa perlu pergantian roda depan kiri, belakang kanan, dan belakang kiri untuk Grandmax 2012. Data dapat di tampilkan secara realtime melalui android. Hasil dari penelitian ini dapat digunakan pada dealer atau tempat reparasi mobil.

\section{Referensi}

[1] T. Wibowo, I. Isranuri, S. Abda, M. Sabri, Indra, A. Hamsi. 2018. studi eksperimental sinyal vibrasi untuk mendeteksi jenis kerusakan bearing ucp-204. Jurnal e-DInamis, Vol. 6: 36-48.

[2] Yandra. E.F, Lapanporo. B.P, Jumarang, M.I. 2016. Rancang Bangun Timbangan Digital Berbasis Sensor Beban $5 \mathrm{Kg}$ Menggunakan Mikrokontroler Atmega328, POSITRON, 6(1), pp $23-28$.

[3] Kelana, M, Muid. A, Nurhasanah. 2015. Rancang Bangun Sistem Pengontrol Intensitas Cahaya pada Ruang Baca Berbasis Mikrokontroler ATMEGA16, POSITRON, 5(1), pp 5-10, 2015.

[4] Wahyudi, T, Soeharsono, Eddy. N. 2016. Mendeteksi kerusakan bantalan dengan menggunakan sinyal vibrasi, SINERGI, 20(2), pp 123-128, 2016. 
[5] Rohman A.Z. 2015. Rancang Bangun Alat Ukur Getaran Mesin berbasis Arduino, Skripsi, Jurusan Teknik Elektro, Universitas Negeri Semarang.

[6] K. Prawiroredjo, S. H. Tirtamihardja. 2013. Rohman A.Z., Rancang Bangun Alat Ukur Getaran Mesin berbasis Arduino, Skripsi, Jurusan Teknik Elektro, Universitas Negeri Semarang, 2015. Tesla. Vol.15, No.2: 103-113

[7] Novianta M.A. 2012, Sistem Deteksi Dini Gempa Dengan Piezo Elektrik Berbasis Mikrokontroler At89c51, Simposium Nasional RAPI XI FT UMS - 2012, E-97, Jurusan Teknik Elektro Institut Sains \& Teknologi AKPRIND Yogyakarta.

[8] Afriani F. 2010. Design Sistem Peringatan Dini Gempa Bumi Menggunakan Sensor Efek Hall UGN3503 berbasis Mikrokontroler ATMEGA8535, Skripsi, FMIPA, UNP

[9] Musta'an M.K. 2011. Sensor Posisi Faraday Untuk Pendeteksi Dini Gempa Pada Gedung , Skripsi, F. Teknik,Universitas islam Indonesia

[10] S. E. Putri, Harmadi. 2017. Rancang Bangun Sistem Pengukuran Frekuensi Getaran Akustik pada Speaker Piezoelektrik Menggunakan Sensor Serat Optik. Jurnal Fisika Unand Vol. 6, No. 1: 47-52 